\section{Oval Versus Circular-Shaped Root Canals: Bond Strength Reached with Varying Post Techniques}

\author{
Mariana Benedetti Ferreira Webber'1, Paula Bernardon'1, Fabiana M.G. França' , \\ Flávia L.B. Amaral' ${ }^{1}$, Roberta T. Basting ${ }^{1}$, Cecilia Pedroso Turssi ${ }^{1}$
}

Division of Cariology and Restorative Dentistry, SLMANDIC - Faculdade São Leopoldo Mandic, Instituto de Pesquisas São Leopoldo Mandic, Campinas, SP, Brazil

Correspondence: Cecilia Pedroso Turssi, Rua José Rocha Junqueira, 13, 13045-755 Campinas, SP, Brasil. Tel: +55-19-3211-3600. e-mail: cecilia.turssi@slmandic.edu.br

\begin{abstract}
The aim of this study was to compare the bond strength (BS) of glass fiber posts (GFP) luted to oval and circular-shaped root canals rehabilitated using varying post techniques, at different intraradicular levels. Ninety 16-mm-long roots of human mandibular premolars, classified either as having oval or circular-shaped canals, were endodontically treated and prepared for restoration using one of three different post techniques $(n=15)$ : 1) single GFP; 2) resin-relined GFP; 3 ) main GFP associated with accessory posts. GFPs were luted with a dual polymerizing resin cement (RelyX ARC) after the canal had been treated with a 3-step etch-and-rinse adhesive system (Adper Scothbond Multipurpose). The samples were sectioned into three 1-mm-thick sections, which were differentiated by the root level (cervical, middle and apical) and tested for push-out BS. Assessment of failure mode was made under a stereomicroscope. Data were analyzed using repeated measures three-way ANOVA and Tukey's test. The root canal cross-section had a significant influence on BS $(p<0.001)$, with the lowest values being observed in oval-shaped canals. The post technique also significantly affected the BS $(p=0.018)$, with the resin-relined GFPs providing the highest BS values in both oval and circular-shaped canals. Irrespective of the cross-section of the root canal and post technique, there was no significant difference in BS in the cervical, middle and apical third of the root canal $(p=0.084)$. In oval-shaped canals, the BS to intraradicular dentin at cervical, middle or apical level could be increased when the GFPs posts were relined.
\end{abstract}

Key Words: intraradicular dentin, glass fiber post, canal cross-section shape, post technique, bond strength.

\section{Introduction}

Endodontically treated teeth may present their coronal structures compromised, which generally requires the use of intraradicular retainers to promote retention of the restoration (1). Glass fiber posts (GFPs) are commonly used with that purpose because they possess modulus of elasticity similar to dentin, which results in biomimicry, allowing therefore, a more uniform tension distribution throughout the radicular dentin and less incidence of unrestorable fractures (2).

However, one of the causes of GFPs failure resides on its decementation (3), which can occur due to the high configuration factor (c-factor) of the root canal. Another reason for decementation is the presence of voids or gaps deriving from the luting process, principally when there is a thicker layer of cement, which can generate high stress at the luting interface, reducing the retention of the GFPs to the root canal (4). The bond strength of the GFP to root dentin can also be exceeded when there is a mismatch between the prepared root canal walls and the GFP, which also increases the thickness of the cement layer resulting in increased stress from volumetric shrinkage (3).

The mismatch between the GPF and the root canal may occur due to widening of the root canal entrance during endodontic treatment, extensive carious lesions, previous restoration and anatomorphological reasons. In respect to the latter, there are reports indicating that 73\% (5) to $100 \%$ (6) of mandibular first premolars have oval/flat canal at the cementoenamel junction and despite the fact that the major/minor aspect ratio reduces along the root from the coronal third to the anatomical apex, making the canals progressively less oval/flat and more circular in shape in the middle and apical third, more than 90\% of mandibular first premolars that are oval- or flat-shaped at the cementoenamel junction still have these cross-sectional configurations up to $2 \mathrm{~mm}$ from the anatomical apex (6).

In face of the mismatch between the post and canal walls in noncircular and flared root canals, a variety of posts and techniques have emerged in order to decrease the thickness of the luting cement. Among them there are the oval-shaped posts that, despite provide thinner cement layer in the apical region (7), do not outperform circular GFPs in oval-shaped canals (8). In flared canals, two techniques have been used to improve GFP retention and reduce the cement thickness: 1) relined technique, which relies on the anatomization of GFP with a composite resin into the root canal (9); 2) accessory post technique, in which additional posts are inserted into the root canal 
along with the main GFP (10). Although such techniques can be effective to improve the biomechanical behavior of flared roots (11), to the authors' best knowledge there is no investigation, as yet, that evaluated the effectiveness of these techniques in oval-shaped root canals.

Despite the fact that one could consider that the findings for flared canals hold for oval-shaped canals, one should bear in mind that in the latter the bonding area is elliptical, not circular tapered, as used in the bond strength calculation formula for flared canals. Therefore, the bonding area in oval-shaped canals is increased, potentially implying in reduction of the bond strength values to intraradicular dentin and increasing the risk of GFP decementation.

Based on the aforementioned rationales, this study compared the bond strength of GFPs luted to oval and circular-shaped root canals rehabilitated using varying post techniques, at different intraradicular levels. The null hypothesis tested was that the bond strength of GFPs to different thirds of the intraradicular dentin would be affected neither by the cross-sectional shape of the root canal nor by the post technique.

\section{Material and Methods}

\section{¿ Experimental Design}

This study followed a completely randomized design, with repeated measures, in a $2 \times 3 \times 3$ factorial scheme, in which the independent variables were: Cross-section shape of the root canal, in two levels (circular and oval); Post technique, in three levels (single, relined and accessory posts); Root third, in three levels (cervical, middle and apical).

The experimental units were ninety mandibular premolar roots, randomly allocated into six groups, formed by the combination of the levels of the factors Crosssection shape of the root canal and Post technique $(n=15)$. From a single experimental unit, three transversal sections were obtained, corresponding to the cervical, middle and apical third of the roots, characterizing an experiment with repeated measurements. The response variables were the push-out bond strength of the GFPs, in MPa. Additionally, the failure mode was characterized qualitatively.

\section{Ethical Aspects and Root Acquisition}

The protocol for this research was reviewed and approved by the local Human Research Ethics Committee under the protocol 1.006.989.

Ninety human mandibular premolars with a single root and single canal were scraped of any residual tissue tags, pumiced, and stored in $0.1 \%$ thymol solution at $4{ }^{\circ} \mathrm{C}$. The teeth were sectioned at the cementoenamel junction with a low-speed diamond saw (Isomet 1000; Buehler Ltda; Bluff, IL, USA), under water cooling in order to obtain 90 16- $\mathrm{mm}$ high roots. The pulp tissue was removed from the root canals with Kerr endodontic files (Dentsply/Maillefer, Petrópolis, RJ, Brazil), under 1\% sodium hypochlorite irrigation.

To ensure the absence of cracks and fractures, the roots were examined under stereoscopic magnifying glass (EK3ST, Eikonal, São Paulo, SP, Brazil). Next, the mesiodistal and buccolingual diameters of the root canals were measured with the digital caliper (MIP/E - 103, Mitutoyo Sul Americana Ltda, Suzano, SP, Brazil). Considering the aspect ratio of the buccolingual measurement divided by the mesiodistal measurement, the roots were classified either as having circular or oval-shaped canals. Roots with 1.00 to 1.99 aspect ratio were assigned into the circular-shaped root canal group (12). Roots with aspect ratios above 2.50 were allocated into the oval-shaped canal group.

The apical portion of the roots was then sealed with Filtek Z250 composite resin (3M ESPE, St. Paul, MN, USA).

\section{Preparation of the Root Canals}

The root canals were endodontically treated using Kerr endodontic files (Dentsply/Maillefer, Petrópolis, RJ, Brazil), under 1\% sodium hypochlorite irrigation. Root canals were obturated with lateral condensed guttapercha using Maillefer tapered digital spacers (Dentsply/ Maillefer, Petrópolis, RJ, Brazil) and the endodontic cement Sealer 26 (Dentsply, Petrópolis, RJ, Brazil). Post space were subsequently prepared, $12 \mathrm{~mm}$ in depth, using the dedicated bur from the GFP kit Exacto $n^{0} 1$ (Angelus, tapered, Londrina, PR, Brazil). The burs were replaced after every five canal root preparations. Afterwards, the root canals were rinsed with distilled water, aspirated with endodontic cannulae, and dried with absorbent paper points.

Prior to the luting procedure, the roots were embedded in condensation-cured silicone (Zetalabor; Zhermack, São Paulo, SP, Brazil) to protect the roots from lights other the curing unit. The post space was treated with a 3-step etch-and-rinse adhesive system. First, the post space was acid etched for 15 seconds with 37\% phosphoric acid (Condac 37, FGM, Joinville, SC, Brazil), rinsed with water for 30 seconds, aspirated with endodontic cannulae and water excesses removed with absorbent paper cones \# 80. Following manufacturer's recommendation, a layer of an activator was applied (Adper Scothbond Multipurpose, 3M ESPE, St. Paul, MN, USA), and dried for $5 \mathrm{~s}$. After that, a layer of the primer was applied (Adper Scothbond Multipurpose, $3 \mathrm{M}$ ESPE, St. Paul, MN, USA) and then dried for 5 seconds. Lastly, a catalyst (Adper Scothbond Multipurpose, 3M ESPE) layer was applied. Excesses were removed with two absorbent paper cones \# 80 after every application.

\section{Luting According the Post Techniques}

Prior to use, the tapered conic GFPs (Exacto $n^{0}$. 1, 
Angelus, Londrina, PR, Brazil and Reforpin, Angelus, Londrina, PR, Brazil - used in the accessory pots technique) were cleaned with $70 \%$ ethanol for $30 \mathrm{~s}$, water rinsed and throughoutly dried. The silane-coupling agent (3M ESPE) was applied in a single layer with a disposable brush and left to air dry.

The dual polymerizing resin cement (RelyX ARC, 3M ESPE) was dispensed on paper blocks, mixed for $10 \mathrm{~s}$, according to the manufacturer's recommendation, and inserted into the root space with aid from a Lentulo spiral filler \# 40 (Dentsply/Maillefer, Ballaigues, Sweden).

For the single technique, the GFP was positioned inside the previously treated post space, perpendicularly to the long axis of the root and manually stabilized for 1 minute. The excess cement was removed $60 \mathrm{~s}$ after the post was settled and light polymerized for $40 \mathrm{~s}$ with a LED curing light Bluephase (Ivoclar Vivadent, Schaan, Liechtenstein) through the post in the occlusal-apical direction. The irradiance of the curing unit was checked with a radiometer and had a mean value of $920 \mathrm{~mW} / \mathrm{cm}^{2}$.

In the relined group, prior to treating the root canals with the 3-step etch-and-rinse adhesive system, they were lubricated with a water-soluble gel (Johnson \& Johnson, São José dos Campos, SP, Brazil). With a $n^{0} 5$ spatula, the composite resin Filtek Z250 was accommodated on the GFP and the ensemble was seated into the post space creating a custom-post. The relined post was light polymerized for $5 \mathrm{~s}$ while still in position and then gently removed from the root canal and light polymerized for an extra $60 \mathrm{~s}$ on each side (buccal, lingual, mesial, and distal). The root canals were then water rinsed to remove the lubricating gel and two absorbent paper points used to keep dentin moist allowing the treatment with the 3-step etch-andrinse adhesive system. The luting procedure was identical to that used for the single post technique.

For the accessory post technique, the treatment of the post space was held as previously stated. Besides the main GFP, the two accessory posts (Reforpin) were also seated into the post space. The luting process was performed as already described.

All samples were stored in $100 \%$ relative humidity at $37^{\circ} \mathrm{C}$, for $48 \mathrm{~h}$.

\section{Push-out Testing}

The samples were fixated on acrylic plates with sculpting wax (Kota, São Paulo, SP, Brazil) in a way that the long axis of the post would be parallel to the plate surface. Following that, the plates were positioned on the low-speed diamond saw. Parallel cuts in the buccolingual direction were made, as to obtain $1.0 \mathrm{~mm}$-thick sections for each root third-cervical, middle and apical. Each slice had its root canal diameter in the buccolingual and mesiodistal directions, and its height measured, with the digital caliper.

To carry out the push-out test, the three sections of each root were placed on a stainless steel metal base, which was attached to a universal test machine (EZ-LX Test, Shimadzu Co., Japan). The referred base has a central orifice with a diameter of $3.0 \mathrm{~mm}$, the sections were placed so that the part corresponding to the post would stay in the same direction of the hole.

A metal rod with a $1.0 \mathrm{~mm}$ diameter active tip attached to a load cell $(50 \mathrm{KN})$ was, then, positioned on the center of the GFP and the push-out bond strength was tested at a $0.5 \mathrm{~mm} / \mathrm{min}$ speed, in the apex to cervical direction, until the post dislodged.

The push-out bond strength values were calculated using the formula $\sigma=F / A$, where $F=$ force registered at the moment the post dislodged, in $\mathrm{Kgf}$, and $\mathrm{A}=$ adhesive interface area, in $\mathrm{mm}^{2}$. To calculate the bonding area of the circular-shaped canals, it was employed the formula of the lateral area of the frustum of a right circular cone with parallel bases formula. For the oval-shaped root canals it was used the area formula of the frustum of ellipse, deducted from the major (buccolingual) and minor (mesiodistal) canal diameter using derivative mathematics.

The bond strength result $(\sigma)$ was initially acquired in $\mathrm{Kgf} / \mathrm{mm}^{2}$ and transformed into $\mathrm{MPa}$, considering the following measure equalization: $1 \mathrm{Kgf} / \mathrm{mm}^{2}=9.8 \mathrm{~N} / \mathrm{mm}^{2}$ $=9.8 \mathrm{MPa}$.

\section{Failure Mode Assessment}

The fractured samples were analyzed for their failure modes in the dentin-cement-resin-post interfaces under a stereomicroscopy (EK3ST, Eikonal, São Paulo, SP, Brazil) at 40x magnification. The failure modes were classified as: adhesive between cement and dentin; adhesive between post and cement; adhesive between post and composite resin; mixed; cohesive in resin cement and cohesive in dentin. For the accessory posts groups, only the main post was taken into consideration to analyze the failure mode.

\section{Statistical Analysis}

In order to compare the effect of the factors under study Cross-section shape of the root canal, Post technique and Root third, likewise their interactions, on the push-out bond strength values, the data were submitted to repeated measures three-way analysis of variance (ANOVA) and to the Tukey's test multiple comparisons. The statistical calculations were performed using the SPSS 23 (SPSS Inc., Chicago, IL, USA) program, adopting the $5 \%$ significance level.

\section{Results}

Table 1 shows the descriptive analysis, in terms of means and standard deviations, of the push-out bond strength 
values of GFPs luted to oval and circular-shaped root canals rehabilitated using varying post techniques, at different intraradicular levels.

The repeated measures three-way ANOVA demonstrated that there was no statistically significant interaction between the independent variables Cross-section shape of the root canal, Post technique and Root third ( $\mathrm{p}=0.560$ ). The double interactions Cross-section shape of the root canal $x$ Post technique $(p=0.717)$, Cross-section shape of the root canal $x$ Root third $(\mathrm{p}=0.572$ ) and Post techniquex Root third ( $p=0.074$ ) were also not statistically significant.

Regardless the post technique and root third, the cross-section shape of the root canal influenced the bond strength of the GFPs $(p<0.001)$, with lower values being observed in oval-shaped canals (mean: $8.00 \mathrm{MPa}$ and standard deviation: $3.79 \mathrm{MPa}$ ) in comparison with the circular-shaped canals (mean: $10.51 \mathrm{MPa}$ and standard deviation: 4.70 MPa).

Table 1. Means (standard deviation) of the push-out bond strength values of glass fiber posts luted to oval and circular-shaped root canals rehabilitated using varying post techniques, at different

\begin{tabular}{|c|c|c|c|}
\hline Canal cross-section & Technique & Level & $\begin{array}{l}\text { Push-out bond } \\
\text { strength (MPa) }\end{array}$ \\
\hline & & Cervical & $10.18(3.33)$ \\
\hline & Single & Middle & $10.22(4.95)$ \\
\hline & & Apical & $10.05(6.57)$ \\
\hline & & Cervical & $8.95(3.34)$ \\
\hline \multirow[t]{9}{*}{ Circular } & Relined & Middle & $13.13(3.31)$ \\
\hline & & Apical & $11.89(5.87)$ \\
\hline & & Cervical & $10.71(3.34)$ \\
\hline & Accessory & Middle & $8.81(3.54)$ \\
\hline & & Apical & $10.76(6.38)$ \\
\hline & & Cervical & $6.92(1.46)$ \\
\hline & Single & Middle & $8.51(4.29)$ \\
\hline & & Apical & $7.83(3.32)$ \\
\hline & & Cervical & $7.18(4.19)$ \\
\hline \multirow[t]{5}{*}{ Oval } & Relined & Middle & $10.38(3.12)$ \\
\hline & & Apical & $10.09(5.43)$ \\
\hline & & Cervical & $6.92(2.00)$ \\
\hline & Accessory & Middle & $7.95(3.21)$ \\
\hline & & Apical & $6.08(4.30)$ \\
\hline
\end{tabular}

The post technique also significantly affected the bond strength of GFPs $(p=0.018)$, with the relined group showing the highest values in both oval and circular-shaped canals, regardless of the root third (Table 2). Lastly, the repeated measures three-way ANOVA also indicated that irrespective of the cross-section type of the root canal and post technique, there was no significant difference in the bond strength values in the cervical, middle and apical third of the root canal ( $p=0.084$; Table 2$)$.

With regards to the failure mode, either in circular or in oval-shaped root canals, for all the post techniques employed, in the cervical and middle third, the majority of the ruptures were adhesive between post and cement, as seen on Figure 1. For the apical portion, in both circular and oval-shaped root canals and for all post techniques, the predominant failure mode was adhesive between cement and dentin. Failures cohesive in resin cement, cohesive in dentin and mixed were also found but in smaller frequencies.

\section{Discussion}

Despite the high survival/success rates of endodontically treated teeth restored with posts (13), the clinical decision on how to rehabilitate oval-shaped root canals poses a challenge to dental practitioners. While testing the null hypothesis that the bond strength of GFPs to different thirds of the intraradicular dentin would be affected neither by the shape of the root canal nor by the post technique, the current results lead to its partial rejection. This arose from the inference that significantly different bond strength values were noticed when comparing oval versus circular-shaped root canals and when contrasting single versus relined versus accessory post techniques, but not when confronting the root thirds among each other.

As can be seen from the results, the bond strength was $23 \%$ lower in oval-shaped canals ( $8.00 \mathrm{MPa}$ ) than in circular counterparts (10.51 MPa). A reason that may explain the lower bond strength of GFPs to oval-shaped canals is the fact that the stress concentration can be higher than in circular-shaped canals, especially in the cervical and middle

Table 2. Means (standard deviation) of the push-out bond strength values of glass fiber posts using varying post techniques, regardless of the cross-section of the root canal and the intraradicular level

\begin{tabular}{ll}
\hline Technique & Means (MPa) \\
\hline Single & $8.95(4.34) \mathrm{ab}$ \\
Relined & $10.25(4.61) \mathrm{a}$ \\
Accessory & $8.57(4.24) \mathrm{b}$ \\
\hline
\end{tabular}

Grand means followed by distinct letters indicate statistically significant difference between techniques. 
third of the palatal aspect (14). However, one should bear in mind that the influence of the GFP elastic modulus cannot be ruled out (14), as stress distribution depends on such property.

Another explanation for the lower bond strength in oval-shaped canals lies in the fact that they present a higher bonding area than the circular-shaped canals. Having the same force been reached in teeth with oval and circular-shaped canals during the mechanical testing, then, in terms of bond strength, the former would present lower values due to its higher bonding area. In the current study, when curiously exploring the force instead of the bond strength data, oval-shaped canals showed a trend to present high force values than circular-shaped canals in the cervical third of the root, but in an overall perspective, this did not imply in higher bond strength values of the GFPs to the oval-shaped canals. This overall result is probably a consequence of the decreasing aspect ratio between the major and minor cross-sections of the root canal in the middle and apical third. In fact, from cone-beam computed tomography (CBCT) images it is known that the major/minor aspect ratio of the canal of mandibular first premolars reduces from the cementoenamel junction to the anatomic apex (5). However, it is worth noting that despite this reduction, a substantial high percentage of non C-shaped mandibular first premolars still present oval/ flat-shaped cross-section in the middle (94.4\%) and apical $(90.7 \%)$ third, as shown by micro-computed tomography

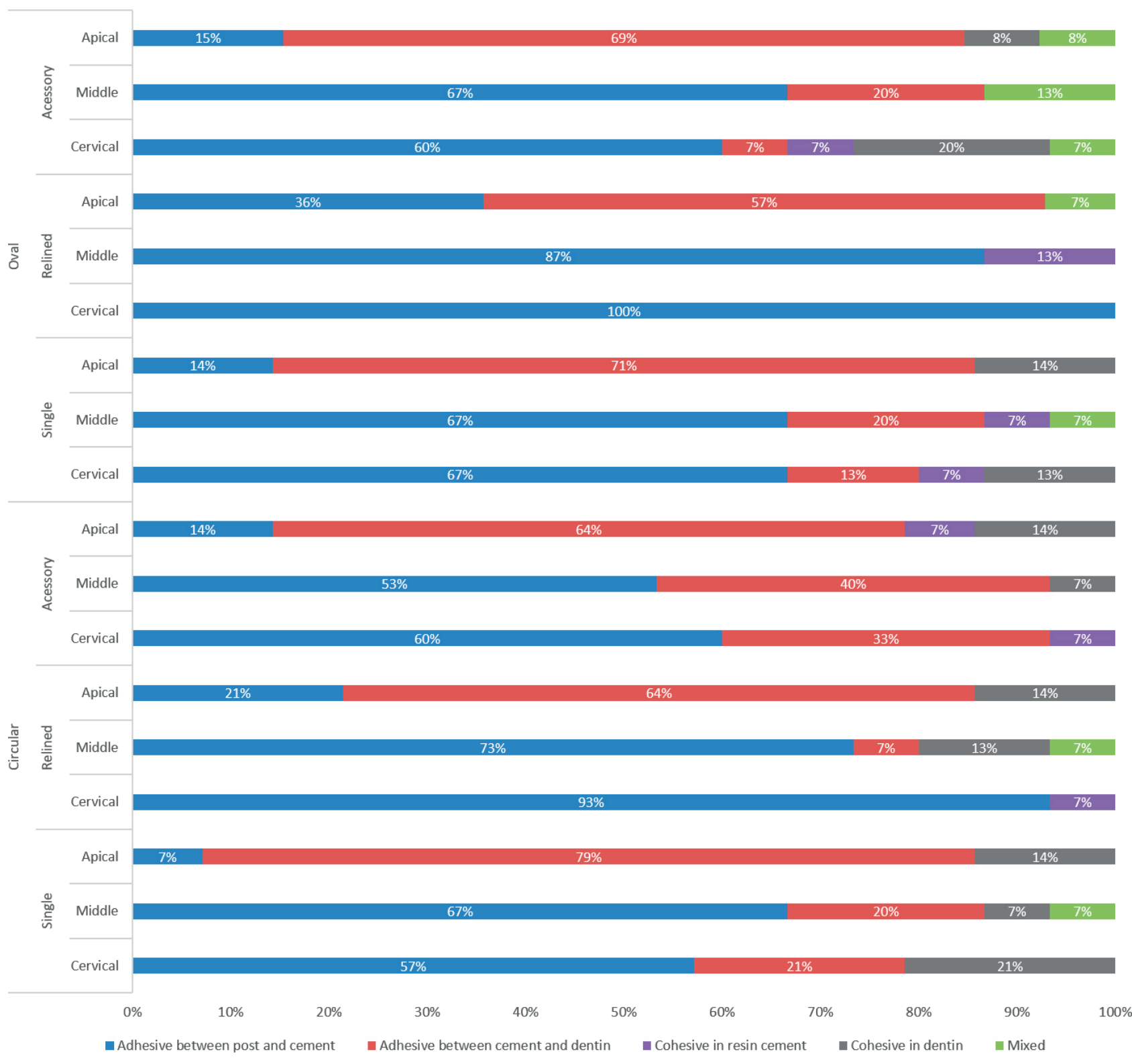

Figure 1. Relative frequency of the failure modes of glass fiber posts luted to oval and circular-shaped root canals rehabilitated using varying post techniques, at different intraradicular levels. 
(micro-CT) (6).

In this study, similar to a previous paper (5), to classify the teeth as having either circular or oval-shaped root canals, the measurements of the mesiodistal and buccolingual diameters of the root canals were made in the cervical area of the root. In another paper (15), researchers radiographed teeth and classified them as oval-shaped based on the measurements of the mesiodistal and buccolingual diameters of root canals within the last $5 \mathrm{~mm}$ from the apex. Although radiographies are nondestructive and easily accessible, in the current study, while trying to use this method to measure the mesiodistal and buccolingual diameters not only at the apical third, but also at the cervical and middle third, it was substantially hard to visualize the canal boundaries in some teeth. Had CBCT or micro-CT been obtained, they could have allowed the measurements of the canal diameters at the different root thirds for their more accurate classification as oval or circular-shaped. However, even using CBCT, Arslan et al. (2015) (5) classified the root canals as circular or ovalshaped based on the measurements of the cross-sections of the cervical third of the root. Therefore, from the point of view of the classification of the root canal shape, the $\succsim$ benefit of using CBCT or micro-CT seems somewhat limited, especially if one considers the costs involved. The advantage in using CBCT and micro-CT would rely on facilitating the bonding area calculation, especially if one considers that deducting the bonding area formula (frustum of ellipse) using the major and minor diameter of the oval-shaped root canal involves derivative mathematics.

Regardless of the root canal cross-section shape, relined GFPs outperformed the technique using accessory posts, as observed elsewhere (10). In fact, relined GFPs customizes the matching between the post and the canal walls, resulting in thinner cement layer, less voids and increased frictional retention (16). Knowing that the effective retention of GFPs to the intraradicular dentin largely derives from sliding friction against the internal walls of root canals rather than true adhesion $(17,18)$, all strategies that increase frictional retention, as provided by relined GFPs, are favorable for the clinical success.

With the accessory post technique, however, despite the reduction in the cement layer thickness (19), it is likely that more voids were created due to the insertion of the accessory posts. In addition, these accessory posts were opaque, which may have reduced the light transmission and thereby the resulting bond strength to the canal walls. In this study, the bond strength value reached with the accessory post technique approached that measured for the single technique, probably because the post spaces were not flared.

Although the bond strength of GFPs to intraradicular dentin did not change from cervical to apical third, in those areas the most frequent failure mode were dissimilar. In the apical third, the most prevalent failure was between cement and dentin, which may be explained by the decreased intratubular penetration of resin cements at this region (20). Probably, the cement-dentin was the most fragile interface because in comparison with the root cervical area the number of dentin tubules is approximately five times lower in the apical third (21). The increased intratubular penetration of the resin cement and thereby the high surface area established between the cement and dentin in the cervical and middle third can also explain why in these locations the most frequent failure occurred between the post and cement, which turned to be the most fragile interface in comparison with the cementdentin counterpart. In addition, the reduced failures at the cement dentin-interface in the cervical and middle third can probably be associated with the presence of less smearlayer and increased cement polymerization in these areas.

Besides the effect of the variables tested herein (Root canal cross-section shape, Post technique and Root third), it is worth noting that other methodological aspects could play a role in the retention of the GFPs to intraradicular dentin. Among them are the adhesive cementation procedures (3). Although when dual polymerizing and selfadhesive cements were systematically reviewed there was no difference in their retention potential (22) and other experimental studies have shown that dual polymerizing cements provide superior bond strength $(23,24)$, the opposite has been found in other studies $(10,25)$. In face of such conflicting results, there is still a need for further research. However, is seems reasonable to exercise that under in vitro conditions in which the root samples would, for example, be immersed in distilled water during cementing to create a moist environment that approaches the clinical setting (25) or even under in vivo conditions, in which the moisture control is an issue, more favorable results could be achieved with the use of a self-adhesive cement, due to its less technique sensitivity (22). In addition to the self-adhesive cements, glass ionomer cements, which has shown promising results due to their ability to chemically bond to dentin (25), may also be considered a potential material for bonding GFPs to intraradicular dentin.

Based on the findings of the present study it can be pointed out that in oval-shaped root canals, the use of relined GFP can improve its bond strength to intraradicular dentin, be it at the cervical, middle or apical third.

\section{Resumo}

0 objetivo deste estudo foi comparar a resistência de união (RU) de pinos de fibra de vidro (PFV), cimentados a condutos com secção transversal ovalada ou circular reabilitados com diferentes técnicas de restauração com 
PFVs, em função do nivel intrarradicular. Noventa raizes de pré-molares inferiores humanos, com $16 \mathrm{~mm}$ de altura, classificadas como possuindo canais ovais ou circulares, foram tratadas endodonticamente e preparadas para serem reabilitadas com uma das três técnicas de restauração com PFVs ( $n=15):$ 1) PFV único, 2) PFV reembasado com resina composta, e 3) PFV principal associado a pinos acessórios. Os PFVs foram cimentados com um agente resinoso de polimerização dupla (RelyX ARC), após o canal ter sido tratado com um sistema adesivo de condicionamento total de três passos (Adper Scothbond Multiuso). As amostras foram seccionadas em três fatias de $1 \mathrm{~mm}$ de espessura, de acordo com o nivel da raiz (cervical, médio e apical)e foram submetidas ao teste de RU por push-out. A análise do modo de falha foi realizada com auxilio de um estereomicroscópio. Os dados foram analisados utilizando-se a ANOVA a três critérios para medidas repetidas e o teste de Tukey. A secção do conduto apresentou influência na RU $(p<0,001)$, com os menores valores sendo observados nos condutos ovalados. A técnica de restauração com PFVs afetou significativamente a $\mathrm{RU}(\mathrm{p}=0,018)$, tendo o PFV reembasado proporcionado os maiores valores de $\mathrm{RU}$, tanto em condutos ovais quanto circulares. Independentemente da secção transversal do conduto radicular e da técnica de restauração com PFV, não houve diferença significativa na RU nos terços cervical, médio e apical $(p=0,084)$. Nos canais de secção transversal ovalada, a RU à dentina intrarradicular nos níveis cervical, médio ou apical aumentou com o emprego de PFVs reembasados.

\section{References}

1. Schwartz RS, Robbins JW. Post placement and restoration of endodontically treated teeth: a literature review. J Endod 2004;30:289301.

2. Goracci C, Ferrari M. Current perspectives on post systems: a literature review. Aust Dent J 2011;56 Suppl 1:77-83.

3. Maroulakos G, He J, Nagy WW. The post-endodontic adhesive interface: theoretical perspectives and potential flaws. J Endod. 2018;44:363-371.

4. Grandini S, Goracci C, Monticelli F, Borracchini A, Ferrari M. SEM evaluation of the cement layer thickness after luting two different posts. J Adhes Dent 2005;7:235-240.

5. Arslan H, Capar ID, Ertas ET, Ertas H, Akcay M. A cone-beam computed tomographic study of root canal systems in mandibular premolars in a Turkish population: theoretical model for determining orifice shape. Eur J Dent 2015;9:11-19.

6. Fan B, Yang J, Gutmann JL, Fan M. Root canal systems in mandibular first premolars with C-shaped root configurations. Part I: Microcomputed tomography mapping of the radicular groove and associated root canal cross-sections. J Endod 2008;34:1337-1341.

7. Muñoz C, Llena C, Forner L. Oval fiber posts do not improve adaptation to oval-shaped canal walls. J Endod 2011;37:1386-1389.

8. Coniglio I, Magni E, Cantoro A, Goracci C, Ferrari M. Push-out bond strength of circular and oval-shaped fiber posts. Clin Oral Investig 2011;15:667-672.

9. Farina AP, Chiela H, Carlini-Junior B, Mesquita MF, Miyagaki DC, Randi Ferraz $\mathrm{CC}$ et al. Influence of cement type and relining procedure on push-out bond strength of fiber posts after cyclic loading. J Prosthodont 2016;25:54-60.
10. Gomes GM, Gomes OM, Gomes JC, Loguercio AD, Calixto AL, Reis A. Evaluation of different restorative techniques for filling flared root canals: fracture resistance and bond strength after mechanical fatigue. J Adhes Dent 2014;16:267-276.

11. Silva GR, Santos-Filho PC, Simamoto-Júnior PC, Martins LR, Mota AS, Soares CJ. Effect of post type and restorative techniques on the strain and fracture resistance of flared incisor roots. Braz Dent J 2011;22:230237.

12. Wu MK, R'oris A, Barkis D, Wesselink PR. Prevalence and extent of long oval canals in the apical third. Oral Surg Oral Med Oral Pathol Oral Radiol Endod 2000;89:739-743.

13. Sarkis-Onofre R, Fergusson D, Cenci MS, Moher D, Pereira-Cenci T. Performance of post-retained single crowns: a systematic review of related risk factors. J Endod 2017:43:175-183.

14. Santos AF, Tanaka CB, Lima RG, Espósito CO, Ballester RY, Braga RR et al. Vertical root fracture in upper premolars with endodontic posts: finite element analysis. J Endod 2009;35:117-120.

15. Uzun I, Keskin C, Özsu D, Güler B, Aydemir H. Push-out bond strength of oval versus circular fiber posts irradiated by erbium-doped yttrium aluminum garnet laser. J Prosthet Dent 2016;116:425-430.

16. Macedo VC, Faria e Silva AL, Martins LR. Effect of cement type, relining procedure, and length of cementation on pull-out bond strength of fiber posts. J Endod 2010;36:1543-1546.

17. Bouillaguet S, Troesch S, Wataha JC, Krejci I, Meyer JM, Pashley DH. Microtensile bond strength between adhesive cements and root canal dentin. Dent Mater 2003;19:199-205

18. Goracci C1, Fabianelli A, Sadek FT, Papacchini F, Tay FR, Ferrari M. The contribution of friction to the dislocation resistance of bonded fiber posts. J Endod 2005;31:608-612.

19. Latempa AM, Almeida SA, Nunes NF, da Silva EM, Guimarães JG, Poskus LT. Techniques for restoring enlarged canals: an evaluation of fracture resistance and bond strength. Int Endod J 2015;48:28-36.

20. García-Gallart M, Llena C, Forner L, Ferrari M. Intratubular penetration in post cementing: A comparative study between a total etching system and a self-etching cement. Am J Dent 2016;29:180-184.

21. Carrigan $\mathrm{PJ}$, Morse $\mathrm{DR}$, Furst $\mathrm{ML}$, Sinai $\mathbf{I H}$. A scanning electron microscopic evaluation of human dentinal tubules according to age and location. J Endod 1984;10:359-363.

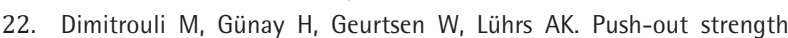
of fiber posts depending on the type of root canal filling and resin cement. Clin Oral Investig 2011;15:273-281.

23. Skupien JA, Sarkis-Onofre R, Cenci MS, Moraes RR, Pereira-Cenci T. A systematic review of factors associated with the retention of glass fiber posts. Braz Oral Res 2015;29:S1806-83242015000100401.

24. Calixto LR, Bandéca MC, Clavijo V, Andrade MF, Vaz LG, Campos EA. Effect of resin cement system and root region on the push-out bond strength of a translucent fiber post. Oper Dent 2012;37:80-86.

25. Pereira JR, Lins do Valle A, Ghizoni JS, Lorenzoni FC, Ramos MB, Dos Reis Só MV. Push-out bond strengths of different dental cements used to cement glass fiber posts. J Prosthet Dent 2013;110:134-140.

Received January 152018 Accepted April 13, 2018 